\title{
Sustainable design using multiobjective optimization of high-strength concrete I-beams
}

\author{
T. García-Segura, V. Yepes \& J. Alcalá \\ Institute of Concrete Science and Technology (ICITECH), \\ Universitat Politècnica de València, Spain
}

\begin{abstract}
Sustainable designs require long-term environmental vision. To this end, this study proposes a methodology to design reinforced concrete I-beams based on multiobjective optimization techniques. The objective functions are the economic cost, the $\mathrm{CO}_{2}$ emissions, the service life, and the overall safety coefficient. The procedure was applied to a simply supported concrete I-beam including several high-strength concrete mix compositions. The solution of this $15 \mathrm{~m}$ beam was defined by a total of 20 variables. Results indicate that highstrength concrete is used for long-term solutions. Further, the economic feasibility of low-carbon structures remaining in service for long periods and ensuring safety is proven. This methodology is widely applicable to different structure designs and therefore, gives engineers a worthy guide to enhance the sustainability of their designs.
\end{abstract}

Keywords: multiobjective optimization, sustainability, high-strength concrete, I-beam, durability.

\section{Introduction}

Optimization methods provide an effective alternative to designs based on experience. To improve the structural design and consequently reduce the material consumption and cost, a trial-and-error process was needed. Over the past few years, greater emphasis has been placed on using heuristic optimization techniques to reduce the cost of walls [1], bridge frames [2], bridge piers [3], road vaults [4] and precast road bridges [5, 6]. However, the design techniques have changed towards an environmental vision. 
The World Commission on Environment and Development (WCED) reported on "Our Common Future" the long-term environmental strategies for achieving sustainable development [7]. From then on, sustainability challenges have gained much attention in all nations. Construction has become one of the main sectors generating greenhouse gases [8]. Consequently, reducing material emissions has been studied from the viewpoint not only of the building construction [8,9], but also structural optimization $[10,11]$.

Sustainability requires the development of the principle of "triple bottom line", which are the social, environmental and economic goals [12]. In this line, this study proposes the economic cost, the $\mathrm{CO}_{2}$ emissions, the service life and the structure safety as target objectives to assess sustainability. Durability, understood as reinforced concrete (RC) decay, depends on carbonation when the structure is exposed to normal conditions. This study focuses on carbonation not only in terms of durability, but also as a $\mathrm{CO}_{2}$ capture. Several studies have addressed the carbon capture $[13,14]$, since $\mathrm{CO}_{2}$ capture during the use stage represents $22 \%$ of the total $\mathrm{CO}_{2}$ emissions [15]. However, this phenomenon has not been included in structural optimization. Thus, this article extends previous analyses of $\mathrm{CO}_{2}$ minimization taken into account carbon capture.

Koumousis and Arsenis [16] introduced the use of multiobjective optimization to concrete structure design. Then, Paya et al. [17] optimized RC building frames applying four objective functions: the economic cost, the constructability, the environmental impact, and the overall safety. Additionally, Martinez-Martin et al. [18] designed RC bridge piers minimizing the economic cost, the reinforcing steel congestion and the embedded $\mathrm{CO}_{2}$ emissions. Both of them proposed a version of multiobjective simulated annealing (MOSA) algorithm to provide efficient solutions to multicriteria problems.

This paper describes a methodology to design sustainable concrete structures based on multiobjective optimization. The structure proposed is a simply supported concrete I-beam defined by 20 discrete variables. One variable defines the concrete strength including high-strength concrete. As an innovative aspect, concrete carbonation during the service life is considered. This leads to carbon capture and therefore, $\mathrm{CO}_{2}$ emission reduction. Likewise, conclusions for longterm structure designs can be drawn including service life and structural safety as objectives in the multiobjective optimization.

\section{Optimization problem definition}

The main goal of the structural multiobjective optimization is to minimize or maximize the objective functions $F$ while satisfying the constraints $G_{j}$ imposed by design codes.

$$
\begin{gathered}
\mathrm{F}(\vec{x}) \\
\mathrm{G}_{\mathrm{j}}(\vec{x}) \leq 0
\end{gathered}
$$

Note that $x$ is the design variable vector. Four objective functions (eqn (1)) are analyzed in pairs. The economic cost and the $\mathrm{CO}_{2}$ emissions are minimized, 
while the service life and the overall safety coefficient are maximized. The constraints or eqn (2) represent all the serviceability limit states (SLSs) and the ultimate limit states (ULSs) that the structure must satisfy. The following sections describe the problem in detail.

\subsection{Design variables and parameters}

The solution of this simply supported concrete I-beam is defined by a total of 20 variables (see fig. 1). Seven variables describe the geometry: the depth $(h)$, the width of top flange $\left(b_{f s}\right)$, the width of bottom flange $\left(b_{f i}\right)$, the thickness of top flange $\left(t_{f s}\right)$, the thickness of bottom flange $\left(t_{f i}\right)$, the web thickness $\left(t_{w}\right)$ and the concrete cover $(r)$. Concrete compressive strength $(f c k)$ varies between $30 \mathrm{MPa}$ and $100 \mathrm{MPa}$. Reinforcing bars are defined by the number of bars $\left(n_{1}, n_{2}, n_{3}\right)$ or the number of bars per meter $\left(n_{4}, n_{5}\right)$ and diameter $\left(\varnothing_{1}, \varnothing_{2}, \varnothing_{3}, \varnothing_{4}, \varnothing_{5}, \varnothing_{6}, \varnothing_{7}\right)$. Note that lower reinforcement is divided in two systems, one covering the whole beam length $\left(n_{2}, \varnothing_{2}\right)$ and another covering the $3 \mathrm{~L} / 5$ central part of the beam $\left(n_{3}\right.$, $\varnothing_{3}$ ). The number of combinations in this study is on the order of $10^{23}$.

The parameters of the I-beam are all the magnitudes taken as fixed data, including the beam span $(15 \mathrm{~m})$, the permanent distributed load $(20 \mathrm{kN} / \mathrm{m})$, and the variable distributed load $(10 \mathrm{kN} / \mathrm{m})$. Durability conditions are the exposure class (IIb), the percentage of occluded air $(<4.5 \%)$ and the use of CEM Portland. Additionally, the beam was considered to be protected against rain.

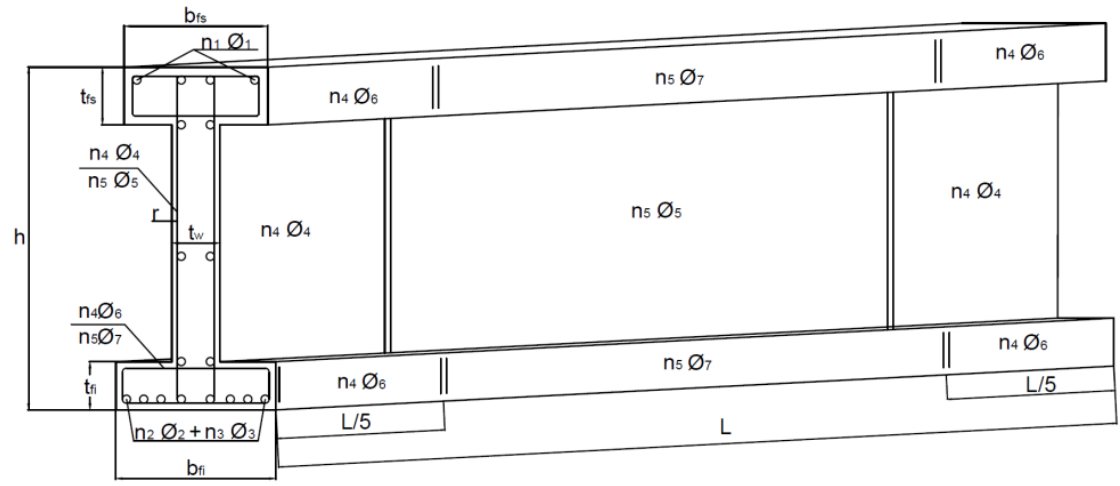

Figure 1: Design variables of the simply supported concrete I-beam.

\subsection{Economic cost function}

This function (eqn (3)) measures the cost (C) as a function of the unit prices $\left(p_{i}\right)$ and the measurements $\left(m_{i}\right)$. The $I c$ units are the concrete, the steel, the formwork, the placing and the $\mathrm{CO}_{2}$ cost. Table 1 summarizes the unit prices obtained from the BEDEC ITEC database of the Institute of Construction Technology of Catalonia [19]. Note that concrete unit price was determined from each mix design, including transport and placing. The cost of $\mathrm{CO}_{2}$ emissions was taken into account and it was that given in $\mathrm{SendeCO}_{2}[20]$. 


$$
\mathrm{C}(\vec{x})=\sum_{i \in I c} p_{i} \cdot m_{i}(\vec{x})
$$

Table 1: Unit prices and $\mathrm{CO}_{2}$ emissions considered in the $\mathrm{RC}$ I-beam.

\begin{tabular}{cccc}
\hline & Unit & Cost (euros) & $\mathrm{CO}_{2}$ emission $(\mathrm{kg})$ \\
\hline $\mathrm{m}^{3}$ & Concrete HA-30 in beams & 97.67 & 259.61 \\
$\mathrm{~m}^{3}$ & Concrete HA-35 in beams & 102.37 & 277.61 \\
$\mathrm{~m}^{3}$ & Concrete HA-40 in beams & 107.07 & 295.61 \\
$\mathrm{~m}^{3}$ & Concrete HA-45 in beams & 111.77 & 313.61 \\
$\mathrm{~m}^{3}$ & Concrete HA-50 in beams & 116.47 & 331.61 \\
$\mathrm{~m}^{3}$ & Concrete HA-55 in beams & 121.17 & 349.61 \\
$\mathrm{~m}^{3}$ & Concrete HA-60 in beams & 125.87 & 367.61 \\
$\mathrm{~m}^{3}$ & Concrete HA-70 in beams & 135.27 & 403.61 \\
$\mathrm{~m}^{3}$ & Concrete HA-80 in beams & 144.67 & 439.61 \\
$\mathrm{~m}^{3}$ & Concrete HA-90 in beams & 154.07 & 475.61 \\
$\mathrm{~m}^{3}$ & Concrete HA-100 in beams & 163.47 & 511.61 \\
$\mathrm{~kg}_{\mathrm{m}}^{2}$ & Steel B-500-SD & 1.24 & 3.03 \\
$\mathrm{~m}$ & Formwork in beams & 33.81 & 2.08 \\
$\mathrm{~m}$ & Beam placing & 16.86 & 39.43 \\
$\mathrm{t} \mathrm{CO}_{2}$ & CO 2 cost & 6.00 & \\
\hline
\end{tabular}

\section{$2.3 \mathrm{CO}_{2}$ emission function}

Emissions (E), measured in $\mathrm{kg} \mathrm{CO}_{2}$, were evaluated similarly to the economic cost. Unit emissions $\left(e_{i}\right)$ are given in Table 1 . The $I e$ units contributing to the structural emissions are the concrete, the steel, the formwork and the placing. Concrete emissions were calculated as the sum of each concrete component emission. Data came from BEDEC ITEC database [19] with the exception of the plasticizer emission which was obtained from the European Federation of Concrete Admixtures Associations [21] and the silica fume which was considered not to produce emissions due to its waste origin.

Carbonation was considered as a $\mathrm{CO}_{2}$ capture, decreasing the embedded $\mathrm{CO}_{2}$ emissions (eqn (4)). The amount of $\mathrm{CO}_{2}$ captured during the service life was estimated by García-Segura et al. [15] based on the predictive models of Fick's First Law of Diffusion and the study of Lagerblad [22] and Collins [23]. Eqn (5) estimates $\mathrm{CO}_{2}$ capture as the product of the carbonation rate coefficient $(k)$, the structure service life $(T)$, the quantity of Portland cement per cubic meter of concrete (c), the amount of $\mathrm{CaO}$ content in Portland cement $(\mathrm{CaO})$ (assumed to be 0.65 ), the proportion of calcium oxide that can be carbonated ( $p$ ) (assumed to be 0.75$)$, the exposed surface area of concrete $(A)$, and the chemical molar fraction $(M)\left(\mathrm{CO}_{2} / \mathrm{CaO}\right.$ is 0.79$)$. The quantity of Portland cement per cubic meter and the carbonation rate coefficient are presented in Table 2 according to $f_{c k}$.

$$
\begin{gathered}
\mathrm{E}(x)=\sum_{i \in I e} e_{i} \cdot m_{i}(\vec{x})-C_{c o 2}(\vec{x}) \\
C_{c o 2}(\vec{x})=k(\vec{x}) * \sqrt{T(\vec{x})} * c(\vec{x}) * C a O * p * A(\vec{x}) * M
\end{gathered}
$$


Table 2: Mix design properties and cement content.

\begin{tabular}{ccc}
\hline Unit & $\mathrm{k}\left(\mathrm{mm} /\right.$ year $\left.^{0.5}\right)$ & Cement $\left(\mathrm{kg} / \mathrm{m}^{3}\right)$ \\
\hline Concrete HA-30 in beams & 3.71 & 280 \\
Concrete HA-35 in beams & 3.01 & 300 \\
Concrete HA-40 in beams & 2.50 & 320 \\
Concrete HA-45 in beams & 2.11 & 350 \\
Concrete HA-50 in beams & 1.81 & 400 \\
Concrete HA-55 in beams & 1.57 & 457 \\
Concrete HA-60 in beams & 1.38 & 485 \\
Concrete HA-70 in beams & 1.09 & 493 \\
Concrete HA-80 in beams & 0.89 & 497 \\
Concrete HA-90 in beams & 0.74 & 517 \\
Concrete HA-100 in beams & 0.63 & 545 \\
\hline
\end{tabular}

\subsection{Service life function}

The durability was evaluated according to the years of concrete service life (T). In this regard, the EHE code [24] was followed based on the Tuutti model [25]. Carbonation is the main factor leading to RC decay. Service life of RC structures was assessed as the sum of two phases, according to eqn (6). The first phase is the initiation of corrosion and the second one involves its propagation.

$$
T(\vec{x})=\left(\frac{r(\vec{x})}{k(\vec{x})}\right)^{2}+\frac{80 \cdot r(\vec{x})}{\emptyset(\vec{x}) \cdot v_{c}}
$$

Note that $T$ are the years of service life, $r$ is concrete cover $(\mathrm{mm}), k$ is the carbonation rate coefficient, $\varnothing$ is the bar diameter $(\mathrm{mm})$, and $v_{c}$ is the corrosion speed $(\mu \mathrm{m} /$ year). In a general exposure, like IIb, the corrosion speed has a value of $2 \mu \mathrm{m} /$ year [24].

\subsection{Overall safety function}

The overall safety (S) evaluates compliance with the code [24], as an overall safety coefficient of 1 implies strict compliance. The coefficient was obtained as the minimum ratio $\gamma_{j}$ between the resistance of the structure and the factored resulting actions affecting resistance for the different limit states (eqn (7)).

$$
S(\vec{x})=\operatorname{Minimum} \gamma_{j}(\vec{x})
$$

\subsection{Structural constraints}

For a given structure, this module checks the structural constraints. Serviceability and ultimate limit states (SLS and ULS) must be guaranteed following the Spanish Standard EHE-08 [24]. Besides, geometrical and constructability constraints are checked. The beam must comply with the SLS for cracking, as the crack width does not exceed the limitation of the existing durability conditions. The instantaneous and time-dependent deflection of the central section is limited to $1 / 250$ of the beam span. Finally, one hundred years are required for the service life. 


\subsection{Multiobjective simulated annealing}

Simulated Annealing (SA) was originally proposed by Kirkpatrick et al [26] based on the analogy of crystal formation. MOSA was adapted from SA algorithm to solve multiobjective problems. The first multiobjective SA algorithm was proposed by Serafini [27]. Pareto set of solutions is characterized as the solutions whose objective values cannot be improved without worsening the value of one objective.

The procedure used can be described as follows. Temperatures for each objective function are calculated following Medina [28] method. After obtaining a feasible solution, a new solution is generated by doing a small random variation to the values of four variables. If it is a feasible solution, Pareto condition is checked. If the criterion is met, the solution is included in Pareto list and updated. The solution will also be accepted if eqn (8) is verified. This process is iterative. It is worth noting that temperature decreases geometrically ( $\mathrm{Te}=\alpha \cdot \mathrm{Te}$ ) by means of a coefficient of cooling $(\alpha)$ once a Markov chain ends. Additionally, the algorithm restarts every five chains from any of the solutions in the Pareto list. Finally, the algorithm finishes when temperature is sufficiently low and no solution is included in the Pareto list in two successive chains.

$$
\text { random }<\prod_{i=1}^{i=2} e^{-\frac{f_{\mathrm{i}, 1}-f_{\mathrm{i}, 0}}{T e_{i}}}
$$

\section{Results}

\subsection{Single objective optimization}

SA was used to optimize the cost and emissions. The calibration recommended Markov chains of 40000 iterations and a cooling coefficient of 0.95 .

Table 3: Beam characteristics for the minimum cost and $\mathrm{CO}_{2}$ emission.

\begin{tabular}{ccc}
\hline & S1 - Cost-optimized & S2 - Emission-optimized \\
\hline $\mathbf{h}(\mathbf{m m})$ & 1250 & 1850 \\
$\mathbf{r}(\mathbf{m m})$ & 17 & 19 \\
$\mathbf{f c k}(\mathrm{MPa})$ & 45 & 30 \\
Steel $(\mathbf{k g})$ & 671.85 & 349.08 \\
Concrete $\left(\mathbf{m}^{3}\right)$ & 2.08 & 2.94 \\
$\mathrm{CO}_{\mathbf{2}}$ capture $\left(\mathbf{k g ~ C O}_{\mathbf{2}}\right)$ & 169.17 & 314.31 \\
Cost $(\boldsymbol{€})$ & 2854.29 & 3263.20 \\
Emission $\left(\mathbf{k g ~ C \mathbf { C O } _ { 2 } )}\right.$ & 3204.17 & 2237.56 \\
Safety coefficient & 1.00 & 1.01 \\
Service life (year) & 150.00 & 107.85 \\
\hline
\end{tabular}

The best solutions for the minimum cost (S1) and $\mathrm{CO}_{2}$ emissions (S2) are summarized in Table 3. $\mathrm{CO}_{2}$ minimization reduces the emissions by $30 \%$ increasing the cost by $14 \%$. For an environmental point of view, bigger sections 
with high depth of low strength concrete and less amount of steel are required. High depth leads to $\mathrm{CO}_{2}$ reduction with regard to increasing the $\mathrm{CO}_{2}$ capture.

\subsection{Multiobjective optimization}

The evolution of Pareto front was studied for establishing the stop criterion. The algorithm was executed until the initial temperature was divided by 500,000 and two consecutive chains finalized without improvement. Further, the algorithm was executed 15 times. Pareto front contains the best solutions after the 15 runs.

\subsubsection{Cost versus emission}

Fig. 2 shows the Pareto front when cost versus emission is studied. Results provide the engineer with intermediate solutions between cost and emission minimization, which are economical and achieve a good $\mathrm{CO}_{2}$ reduction. For example, increasing the cost by $1 \%$ and $7 \%$ in solutions S3 and S4 (see Table 4), results in saving of $15 \%$ and $25 \% \mathrm{~kg} \mathrm{CO}_{2}$, comparing to solution $\mathrm{S} 1$. Pareto set of solutions shows two linear relations between objectives. Firstly, an increase in initial cost leads to more efficient $\mathrm{CO}_{2}$ reduction. As a rule of thumb, one euro increase in the cost results in saving of $13.79 \mathrm{~kg} \mathrm{CO}_{2}$. From $2900 €$, increasing one euro reduces the emissions in $1.15 \mathrm{~kg} \mathrm{CO}_{2}$.

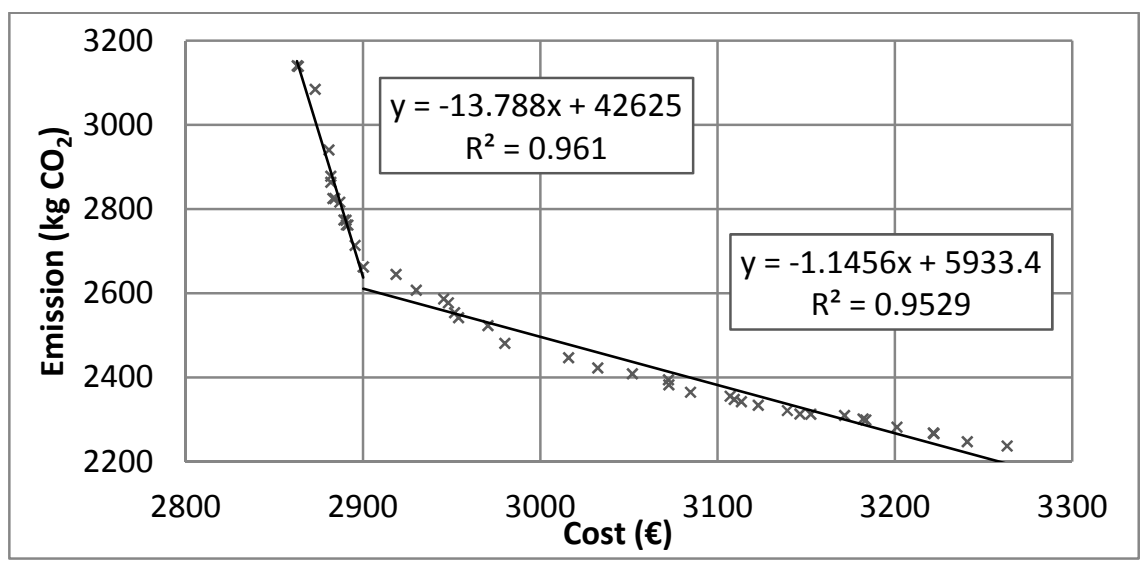

Figure 2: Cost versus emission - Pareto front.

\subsubsection{Cost versus service life}

Findings indicate that an insignificant increase in cost leads to an important extension in service life. The characteristics of the most durable solution (S5) are summarized in Table 4 . Increasing the cost by $1 \%$ could multiply the service life about three times. It is worth noting that to achieve 500 years, concrete cover is enlarged from $17 \mathrm{~mm}$ to $19 \mathrm{~mm}$ and concrete strength is increased to $80 \mathrm{MPa}$. Fig. 3 shows the linear correlation ( $\mathrm{T}=10.355 \mathrm{C}-29429)$. It means that raising the cost by one euro results in extending the service life by ten years. 
Table 4: Beam characteristics for the MOSA results.

\begin{tabular}{|c|c|c|c|c|c|c|}
\hline & S3 & S4 & S5 & S6 & S7 & S8 \\
\hline h (mm) & 1450 & 1700 & 1250 & 1350 & 1750 & 2050 \\
\hline $\mathbf{r}(\mathbf{m m})$ & 19 & 17 & 19 & 17 & 29 & 19 \\
\hline fck (MPa) & 35 & 35 & 80 & 45 & 55 & 35 \\
\hline Steel (kg) & 518.11 & 403.47 & 666.79 & 891.22 & 343.70 & 435.21 \\
\hline Concrete $\left(\mathrm{m}^{3}\right)$ & 2.34 & 2.55 & 1.90 & 2.16 & 3.27 & 3.08 \\
\hline $\begin{array}{c}\mathrm{CO}_{2} \text { capture } \\
\left(\mathrm{kg} \mathrm{CO}_{2}\right)\end{array}$ & 203.65 & 236.32 & 185.23 & 179.62 & 417.68 & 285.32 \\
\hline Cost $(€)$ & 2895.48 & 3051.89 & 2891.70 & 3240.80 & 3169.69 & 3553.15 \\
\hline Emission $\left(\mathrm{kg} \mathrm{CO}_{2}\right)$ & 2713.78 & 2409.11 & 3356.93 & 3889.76 & 2486.74 & 2630.02 \\
\hline Safety coefficient & 1.00 & 1.02 & 1.01 & 1.50 & 1.01 & 1.50 \\
\hline Service life (year) & 109.04 & 109.04 & 500.00 & 150.00 & 500.00 & 109.04 \\
\hline
\end{tabular}

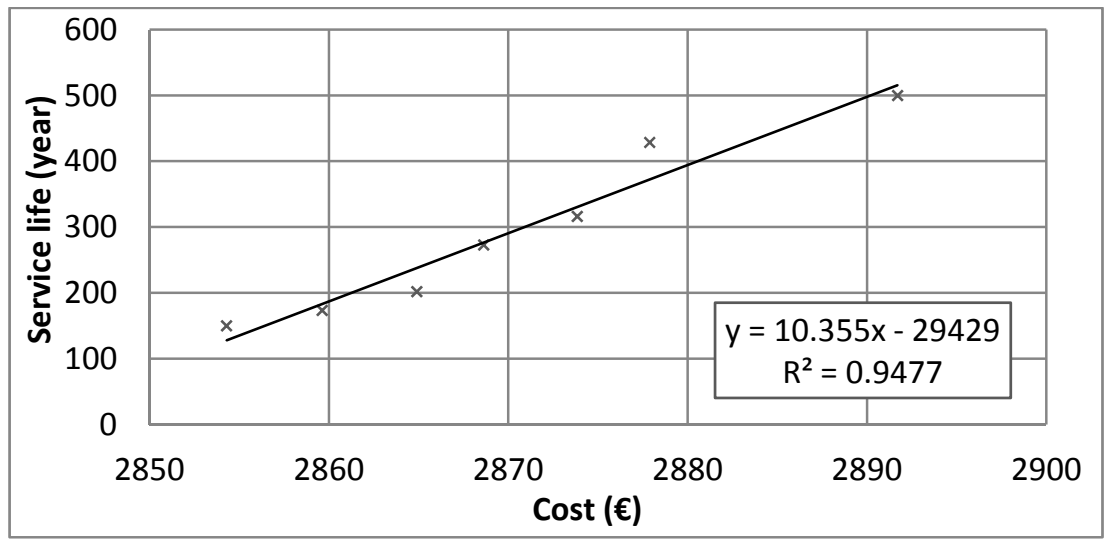

Figure 3: Cost versus service life - Pareto front.

\subsubsection{Cost versus safety}

Structural safety can be improved with a cost effort. Fig. 4 shows the Pareto front, which is represented by a linear function $(\mathrm{S}=0.0016 \mathrm{C}-3.736)$. A solution with about $50 \%$ (S6) higher overall safety factor is given in Table 4 . This means a cost increment of $14 \%$, given the higher amount of reinforcement.

\subsubsection{Emission versus service life}

The characteristics of Pareto optimal set differ from the economical results described in Section 3.2.2. For this objective, lengthening concrete cover is more efficient than increasing concrete strength. The interpretation of these results is similar to the one given for the single objective optimization. High strength concrete is not a good alternative from an environmental point of view. 
However, this is a good option for durability improvement. Concrete is $55 \mathrm{MPa}$ characteristic strength in solution S7, which has 500 years of service life. This solution increases the service life by $364 \%$ with $11 \%$ more $\mathrm{CO}_{2}$ emissions. Two linear relations may be used to describe the trend: one with lower gradient up to 250 years of service life, and other more pronounced to 500 years.

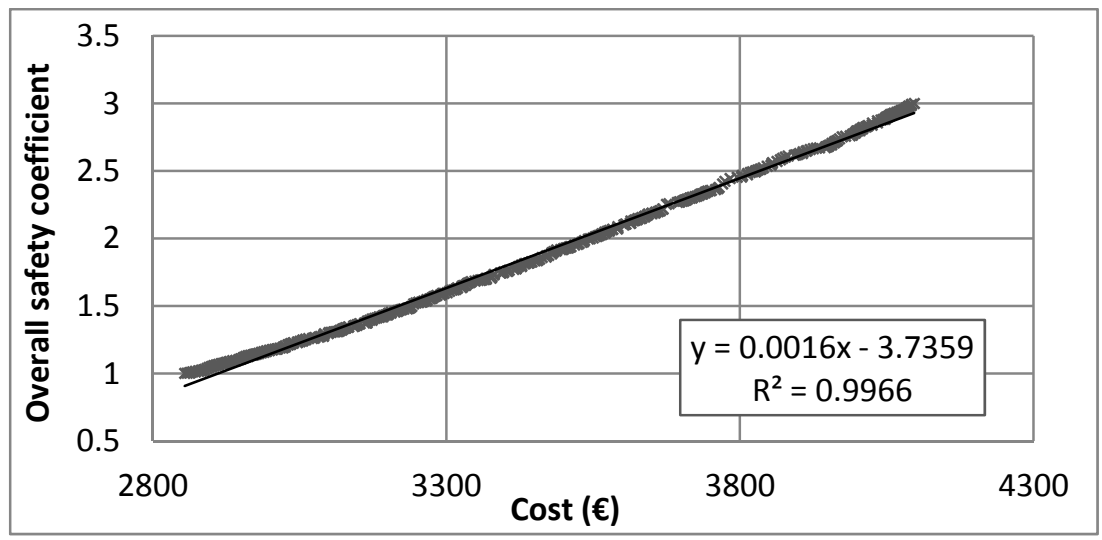

Figure 4: Cost versus safety - Pareto front.

\subsection{5}

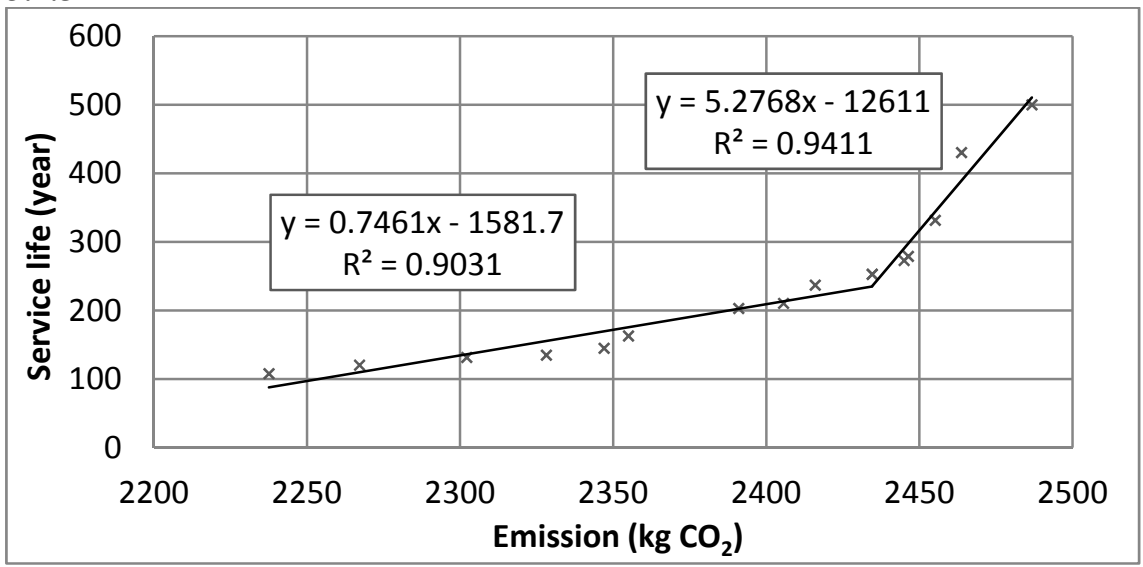

Figure 5: Emission versus service life - Pareto front.

\subsubsection{Emission versus safety}

Fig. 6 shows the effect of the overall safety factor on the emissions. A linear fit between both objectives $(\mathrm{S}=0.0015 \mathrm{E}-2.348)$ is found. Solution $\mathrm{S} 8$ with an overall safety factor of 1.5 emits $18 \%$ more $\mathrm{CO}_{2}$ than the one with a factor of one. 


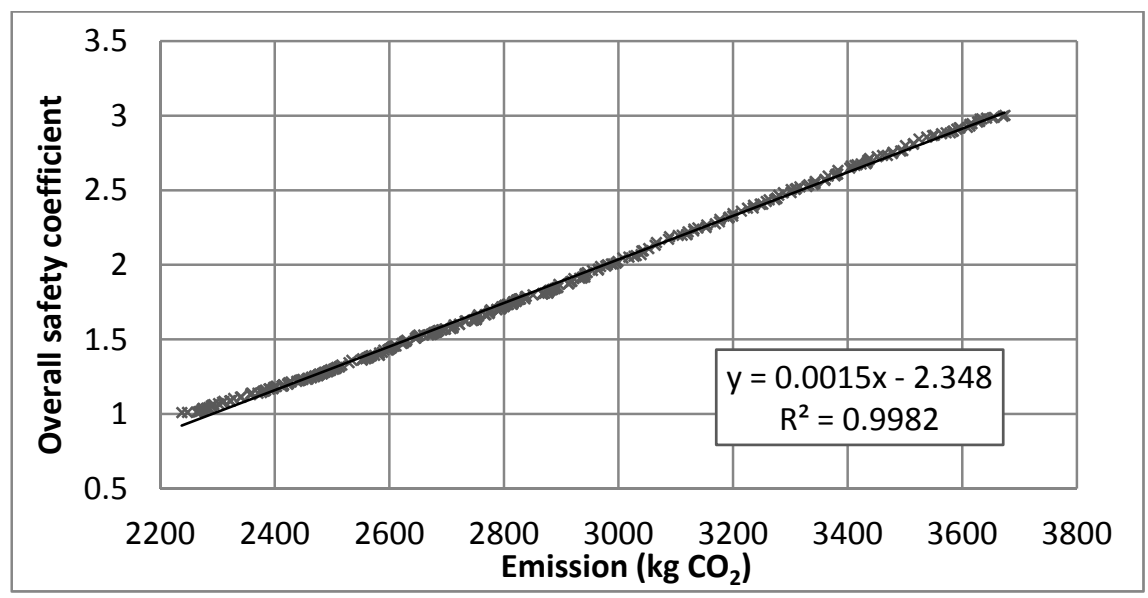

Figure 6: Emission versus safety - Pareto front.

\section{Conclusions}

Single objective optimization gives good solutions for one objective, while the others remain in disadvantage. Alternatively, MO provides a set of optimal solutions for two objectives. Highlighted by this study are solutions which save up to $15 \%$ and $25 \% \mathrm{~kg} \mathrm{CO}_{2}$ with a resulting increase in the cost of about $1 \%$ and $7 \%$. Besides, service life may be multiplied by three or five, increasing respectively the cost and the emissions by 1 and $11 \%$.

The analysis of the structure characteristics leads to the definition of general rules. For instance, increasing concrete strength to improve durability makes good economic sense. However, bigger concrete cover is more acceptable from an environmental point of view. Emission optimization leads to low strength concrete and big sections with high depth and less amount of steel, comparing to cost-optimized solutions. The higher exposed surface area, the more $\mathrm{CO}_{2}$ capture.

This methodology provides an approach to sustainable structural design. For an environmental point of view, not only emissions should be reduced but also durability plays a significant role. Durability reduces the maintenance cost and lengthens concrete service life. This leads to a small annual cost and emission, as well as, a reduction in long-term material consumption. Findings indicate that durable structures can be designed without trade-offs in price or emissions.

\section{Acknowledgement}

This research was financially supported by the Spanish Ministry of Science and Innovation (Research Project BIA2011-23602). 


\section{References}

[1] Yepes, V., Alcala, J., Perea, C. \& Gonzalez-Vidosa, F., A parametric study of optimum earth retaining walls by simulated annealing. Engineering Structures, 30(3), pp. 821-830, 2008.

[2] Perea, C., Alcala, J., Yepes, V., Gonzalez-Vidosa, F. \& Hospitaler, A., Design of reinforced concrete bridge frames by heuristic optimization. Advances in Engineering Software, 39(8), pp. 676-688, 2008.

[3] Martinez, F.J., Gonzalez-Vidosa, F., Hospitaler, A. \& Alcala, J., Design of tall bridge piers by ant colony optimization. Engineering Structures, 33(8), pp. 2320-2329, 2011.

[4] Carbonell, A., Gonzalez-Vidosa, F. \& Yepes, V., Design of reinforced concrete road vaults by heuristic optimization. Advances in Engineering Software, 42(4), pp. 151-159, 2011.

[5] Martí, J.V., González-Vidosa, F., Yepes, V. \& Alcalá, J., Design of prestressed concrete precast road bridges with hybrid simulated annealing. Engineering Structures, 48, pp. 342-352, 2013.

[6] Martí, J.V., Yepes, V. \& González-Vidosa, F., A memetic algorithm approach to designing of precast-prestressed concrete road bridges with steel fiber-reinforcement. Journal of Structural Engineering ASCE, 2014 (accepted, in press).

[7] United Nations. Report of the World Commission on Environment and Development: Our Common Future, 1987. www.are.admin.ch/themen /nachhaltig/00266/00540/00542/index.html?lang=en.

[8] Liu, S., Tao, R. \& Tam, C.M., Optimizing cost and $\mathrm{CO}_{2}$ emission for construction projects using particle swarm optimization. Habitat International, 37, pp. 155-162, 2013.

[9] González, M.J. \& Navarro, J.G., Assessment of the decrease of $\mathrm{CO}_{2}$ emissions in the construction field through the selection of materials: Practical case study of three houses of low environmental impact. Building and Environment, 41(7), pp. 902-909, 2006.

[10] Yepes, V., González-Vidosa, F., Alcalá, J. \& Villalba, P., $\mathrm{CO}_{2^{-}}$ Optimization Design of Reinforced Concrete Retaining Walls based on a VNS-Threshold Acceptance Strategy. Journal of Computing in Civil Engineering, 26(3), pp. 378-386, 2012.

[11] Camp, C.V. \& Huq, F., $\mathrm{CO}_{2}$ and cost optimization of reinforced concrete frames using a big bang-crunch algorithm. Engineering Structures, 48, pp. 363-372, 2013.

[12] Elkington, J., Cannibals with Forks: The Triple Bottom Line of 21st Century. Gabriola Island, BC: New Society Publishers, 1998.

[13] Börjesson, P. \& Gustavsson, L., Greenhouse gas balances in building construction: wood versus concrete from life cycle and forest land-use perspectives. Energy Policy, 28(9), pp. 575-588, 2000.

[14] Collins, F. Inclusion of carbonation during the life cycle of built and recycled concrete: influence on their carbon footprint. The International Journal of Life Cycle Assessment, 15(6), pp. 549-556, 2010. 
[15] García-Segura, T., Yepes, V. \& Alcalá, J., Life-cycle greenhouse gas emissions of blended cement concrete including carbonation and durability. The International Journal of Life Cycle Assessment, 19(1), pp. 3-12, 2014.

[16] Kousmousis, V. \& Arsenis, J., Genetic algorithms in optimal detailed design of reinforced concrete members. Computer-Aided Civil and Infrastructure Engineering, 13, pp. 43-52, 1998.

[17] Paya, I., Yepes, V., González-Vidosa, F. \& Hospitaler, F., Multiobjective Optimization of Reinforced Concrete Building Frames by Simulated Annealing. Computer-Aided Civil and Infrastructure Engineering, 23(8), pp. 596-610, 2008.

[18] Martinez-Martin, F., Gonzalez-Vidosa, F., Hospitaler, A. \& Yepes, V., Multi-objective optimization design of bridge piers with hybrid heuristic algorithms. Journal of Zhejiang University Science A, 13(6), pp. 420-432, 2012.

[19] Catalonia Institute of Construction Technology. BEDEC PR/PCT ITEC materials database. Barcelona, Spain. www.itec.cat

[20] SendeC $\mathrm{C}_{2}$. Sistema electrónico de negociación de derechos de emisión de dióxido de carbono. www.sendeco2.com

[21] European Federation of Concrete Admixtures Associations. Environmental Product Declaration (EPD) for Normal Plasticising admixtures, 2006. www.efca.info/downloads/324\%20ETG\%20Plasticiser $\% 20$ EPD.pdf.

[22] Lagerblad, B., Carbon dioxide uptake during concrete life-cycle: State of the art. Swedish Cement and Concrete Research Institute, Stockholm, 2005.

[23] Collins, F., Inclusion of carbonation during the life cycle of built and recycled concrete: influence on their carbon footprint. The International Journal of Life Cycle Assessment, 15(6), pp. 549-556, 2010.

[24] Fomento, M., Code on structural concrete EHE-08, Ministerio de Fomento, Madrid, Spain, 2008. (in Spanish).

[25] Tuutti, K., Corrosion of steel in Concrete. CBI Forskning Research Report, Cement and Concrete Research Institute, Stockholm, Sweden, 1982.

[26] Kirkpatrick, S., Gelatt, C.D. \& Vecchi, M.P., Optimization by simulated annealing. Science, 220(4598), pp. 671-680, 1983.

[27] Serafini, P., Simulated Annealing for multiple objective optimization problems. Proceedings of the Tenth International Conference on Multiple Criteria Decision Making, Taipei, pp. 87-96, 1992.

[28] Medina, J., Estimation of incident and reflected waves using simulated annealing, Journal of Waterway, Port, Coastal, and Ocean Engineering, 127(4), pp. 213-21, 2001. 